\title{
REPRESENTAÇÕES SOCIAIS SOBRE EDUCAÇÃO EM SAÚDE DE AGENTES COMUNITÁRIOS: PISTAS PARA EDUCAÇÃO PERMANENTE
}

Christiano Adson Barbosa Lima', Antonio Luís Parlandin dos Santos², Arlete Marinho Gonçalves², Elizabeth Teixeira ${ }^{4}$, Horácio Pires Medeiros ${ }^{5}$

\begin{abstract}
RESUMO: Estudo de natureza qualitativa teve por objetivo analisar a estrutura das representações sociais de educação em saúde de agentes comunitários de saúde da cidade de Oriximiná - Pará; adotou-se como referencial a Teoria das Representações Sociais, numa perspectiva estrutural. Os dados foram coletados por meio de evocação livre à expressão educação em saúde de 61 agentes comunitários de saúde, processados pelo software EVOC2003 e analisados por meio do quadro de quatro casas. Os resultados indicam uma estrutura representacional positiva, revelando como elementos centrais da representação os termos prevenção e orientação, e apontam-se questões para nortear processos de educação permanente. Conclui-se que as representações estão relacionadas à teia complexa que envolve o agir dos agentes comunitários em saúde.
\end{abstract}

PALAVRAS-CHAVE: Educação em saúde; Educação continuada; Agentes comunitários de saúde.

\section{SOCIAL REPRESENTATIONS ABOUT HEALTH EDUCATION AMONG COMMUNITY HEALTHCARE ASSISTANTS: COURSES OF ACTION FOR PERMANENT EDUCATION}

ABSTRACT: This qualitative study had as its aim to analyse the structure of social representations of health education among community healthcare assistants in the city of Oriximiná in the state of Pará. The Theory of Social Representations was adopted as a framework, in a structural perspective. Data were collected via Vergés' free association with the phrase health education among 61 community healthcare assistants, processed by the EVOC2003 software and analyzed by a Vergés fourquadrant chart. The results point to a positive representational structure, with the terms prevention and orientation appearing as central representational elements, and raise questions for guiding processes of permanent education. It is concluded that the representations are related to a complex web involving community healthcare assistants' actions.

KEYWORDS: Health education; Continuing education; Community healthcare assistants.

\section{REPRESENTACIONES SOCIALES ACERCA DE LA EDUCACIÓN EN SALUD DE AGENTES COMUNITARIOS: PISTAS PARA EDUCACIÓN PERMANENTE}

RESUMEN: Estudio de naturaleza cualitativa que tuvo el objetivo de analizar la estructura de las representaciones sociales de educación en salud de agentes comunitarios de salud de la ciudad de Oriximiná - Pará; fue adoptada como referencial la Teoría de las Representaciones Sociales, en una perspectiva estructural. Los datos fueron recogidos por medio de evocación libre a la expresión educación en salud de 61 agentes comunitarios de salud, y procesados por software EVOC2003 y analizados por medio del "cuadro de cuatro casas". Los resultados apuntan una estructura representacional positiva, revelando como elementos centrales de la representación los términos prevención y orientación. Se apuntan cuestiones para nortear procesos de educación permanente. Se concluye que las representaciones están relacionadas a la tela compleja que involucra el actuar de los agentes comunitarios en salud. PALABRAS-CLAVE: Educación en salud; Educación continuada; Agentes comunitarios de salud.

* Extraído da pesquisa "Conhecimento-procedimentos-representações de agentes comunitários de saúde e produção-validação de tecnologias educativas, a favor da educação permanente no/do/para o SUS", que atendeu ao Edital PPSUS 2007-2009 do MS/CNPq/ Fundação de Apoio à Pesquisa do Estado do Pará.

'Enfermeiro da Secretaria Municipal de Saúde de Oriximiná- Pará.

${ }^{2}$ Enfermeiro. Mestre em Educação. Professor da Escola Superior Madre Celeste. Membro do Grupo de Pesquisa Práticas Educativas em Saúde e Cuidado na Amazônia-PESCA.

${ }^{3}$ Pedagoga. Mestre em Educação. Professora da Universidade Federal do Pará. Líder do Grupo de Estudos e Pesquisas da Educação Especial. ${ }^{4}$ Enfermeira. Doutora em Ciências. Professora da Universidade do Estado do Pará - UEPA. Líder do PESCA.

${ }^{5}$ Acadêmico de Enfermagem da UEPA. Membro do PESCA.

Autor correspondente:

Recebido: 25/03/2011

Elizabeth Teixeira

Aprovado: $31 / 01 / 2012$

Universidade do Estado do Pará

Rua Municipalidade, 949 - 66050-350 - Belém-PA-Brasil

E-mail: etfelipe@terra.com.br 


\section{INTRODUÇÃO}

A educação em saúde é um tema que vem ganhando valorização no contexto das problemáticas levantadas em pesquisas no campo da saúde com interface na educação. A educação em saúde é considerada um campo de práticas e de conhecimento do setor saúde que tem se ocupado mais diretamente com a criação de vínculos entre a ação assistencial e o pensar-fazer cotidiano da população $0^{(1)}$.

Entende-se por educação em saúde quaisquer combinações de experiências de aprendizagem delineadas com vistas a facilitar ações voluntárias conducentes à saúde. A educação em saúde é, sob o ponto de vista dominante e tradicional, uma área de saber técnico, ou seja, uma organização dos conhecimentos das ciências sociais e da saúde voltada para instrumentalizar o controle dos doentes pelos serviços e a prevenção de doenças pelas pessoas ${ }^{(2)}$. A partir desse e de outros pontos de vista, afirma-se que a educação em saúde é um campo multifacetado, para o qual convergem diversas concepções, tanto da área da educação quanto da saúde, as quais espelham diferentes compreensões de mundo, demarcadas por distintas posições políticofilosóficas sobre o homem e a sociedade.

Nessa perspectiva, contra o ponto de vista dominante e tradicional, somos a favor de uma educação popular em saúde. Essa não visa a criar sujeitos subalternos educados - sujeitos limpos, polidos, alfabetizados, bebendo água fervida e utilizando fossas sépticas- mas visa a instigar nos atores sociais a busca pelo entendimento da realidade, sobre a sua inserção na sociedade e formas de transformar a realidade em que vive ${ }^{(1)}$.

Nesse contexto, surge um ator social que tem grande destaque nas práticas de educação em saúde: o Agente Comunitário de Saúde (ACS). Esse é um trabalhador que atua na Estratégia Saúde da Família (ESF), a qual consolida-se no contexto da municipalização e descentralização das ações de atenção primária à saúde no Brasil ${ }^{(3)}$.

Para o Ministério da Saúde, o ACS é um trabalhador que faz parte da equipe de saúde da comunidade onde mora e precisa estar preparado para orientar famílias sobre cuidados com sua própria saúde, e também com a saúde da comunidade. Sem dúvida, esse apresenta características especiais, uma vez que atua na mesma comunidade onde vive, tornando mais forte a relação entre trabalho e vida social ${ }^{(4)}$.

Dentre as atribuições dos ACS, definidas pelo Ministério da Saúde, duas merecem atenção especial quando se discute a educação permanente. A primeira, afirma que os ACS devem orientar as famílias para a utilização adequada dos serviços de saúde; a segunda salienta que devem informar os demais membros da equipe de saúde acerca da dinâmica social da comunidade, suas disponibilidades e necessidades ${ }^{(4)}$. Curiosamente, nessas duas atribuições pode-se identificar um movimento bidirecional dos agentes que, de um lado, informam à população modos de fazer estabelecidos pelo sistema de saúde oficial e que, de outro, munem os profissionais de saúde de elementos-chave para a compreensão dos problemas de saúde das famílias e das necessidades da população.

Os ACS, em seu dia-a-dia nas comunidades em que atuam, operam um agir cuidativo-educativo, guiado por suas representações. Se houver uma aproximação da estrutura dessas representações pode-se pensar (a partir delas) processos de educação permanente. As representações indicam as imagens que os sujeitos têm de objetos (materiais e imateriais) que circulam no seu cotidiano, norteiam suas atitudes, são veiculadas em seu universo consensual - entre pares de seus grupos de pertença - e podem ser ressignificadas em processos de formação. Processos esses que os/as enfermeiros/as precisam planejar e desenvolver.

No sentido de qualificar o cuidado à saúde, o Ministério da Saúde atribui ao enfermeiro a responsabilidade de supervisionar, coordenar e realizar atividades de educação permanente dos ACS. A educação permanente se configura em uma ação estratégica para a aprendizagem coletiva a partir das práticas e do trabalho, oportunizando o diálogo e a cooperação entre os profissionais, serviços, gestão, atenção, formação e controle social, potencializando o enfrentamento e a resolução de problemas com qualidade ${ }^{(5)}$.

As formas de capacitar os ACS têm despertado interesse por ser exigido deste profissional o enfrentamento de conflitos que cotidianamente aparecem em função de sua carência de habilidades relacionadas à identificação das necessidades de saúde e dinâmica social da comunidade. Rever formas de capacitação para os ACS significa rever as concepções pedagógicas que compreendem a prática como mera aplicação do saber, numa visão dissociada entre teoria e prática, entre o pensar e o fazer, reproduzindo a fragmentação do processo de trabalho ${ }^{(5)}$.

A preocupação com a educação permanente dos ACS tem atraído atenção especial de diversas áreas, dentre elas a Enfermagem, incentivando a realização de estudos a partir da perspectiva desses sujeitos, que são ouvidos sobre suas práticas de trabalho com as comunidades em 
que atuam. Diante do exposto, elegemos como objetivo de estudo analisar a estrutura das representações sociais de ACS acerca da educação em saúde.

\section{MÉTODO}

Para o alcance dos objetivos realizou-se um estudo descritivo pautado numa abordagem qualitativa, com pesquisa de campo, apoiado na Teoria das Representações Sociais, complementado com subsídios da Teoria do Núcleo Central ou Abordagem Estrutural das Representações Sociais ${ }^{(6)}$. A pesquisa qualitativa é o desenvolvimento de conceitos que nos ajudam a compreender um fenômeno social num cenário natural em vez de experimental, dando ênfase adequada aos seus significados, experiências e olhar dos participantes ${ }^{(7)}$.

As representações sociais são conceitos, explicações e proposições oriundas da vida cotidiana e das interações e comunicações; são "ciências coletivas sui generis destinadas à interpretação e à elaboração do real"(6:31).

Os sujeitos estudados foram 61 ACS (de um total de 90) lotados na Secretaria Municipal de Saúde do Município de Oriximiná, na região oeste do Pará. Quanto à faixa etária obtivemos um percentual de $49 \%$ de agentes com mais de 41 anos de idade; $69 \%$ do gênero feminino; $75 \%$ com tempo de serviço correspondente à faixa de 1 a 5 anos, o que significa um conjunto de ACS adulto-maduros, em início de carreira e, predominantemente, do sexo feminino. Os sujeitos foram convidados a participar da pesquisa durante atividade de atualização realizada pela Secretaria, o que facilitou o contato com ACS que atuam tanto na área urbana como na área rural do município.

A coleta de dados ocorreu no mês de fevereiro de 2009. Os princípios éticos foram observados e seguidos com base na Resolução 196/96; todos os sujeitos participantes do estudo foram convidados, informados dos objetivos, procedimentos e formalizaram a participação. O projeto foi aprovado pelo Comitê de Ética em Pesquisa do Curso de Graduação em Enfermagem da Universidade do Estado do Pará sob Protocolo n. 022/2008.

Tendo por base as propriedades qualitativas e quantitativas na determinação dos elementos centrais e periféricos de uma representação, a coleta de dados pautou-se na técnica de evocações ou associação livre guiada pelo termo indutor educação em saúde. Esta técnica também é conhecida como teste da evocação livre e se enquadra entre os métodos associativos usados nos estudos das representações sociais. Os métodos associativos se fundamentam em expressões verbais, colhidas na forma mais espontânea, menos controlada e, por hipótese, mais autênticas ${ }^{(6)}$.

Foi solicitado aos ACS que escrevessem até cinco palavras que viessem às suas mentes quando ouviam o referido termo indutor. As evocações obtidas foram processadas pelo software EVOC 2003. Os dados foram analisados a partir de sua distribuição no quadro de quatro casas, que se organiza em torno do cruzamento de duas informações: as palavras mais frequentes e mais prontamente evocadas pelos sujeitos, que se localizam no núcleo central, bem como as menos prontamente evocadas, que se localizam na periferia da representação( ${ }^{(6)}$.

$\mathrm{O}$ núcleo central tem uma função geradora e organizadora, ou seja, é o elemento pelo qual se cria ou se transforma a significação dos outros elementos constitutivos da representação e é por ele que esses elementos tomam um sentido, um valor. O núcleo central é determinado, por um lado, pela natureza do objeto representado e, por outro, pela relação que o sujeito mantém com esse objeto. É um subconjunto da representação constituído por um ou vários elementos, cuja ausência desestruturaria ou daria uma significação diferente à representação em seu conjunto ${ }^{(6)}$.

Em torno do núcleo central, organizam-se os elementos periféricos $\left(1^{\mathrm{a}} \mathrm{e} 2^{\mathrm{a}}\right.$ periferia) da representação que, provendo a interface entre a realidade concreta e o sistema central, atualiza e contextualiza as determinações normativas do núcleo central. É nele, portanto, que devem se concentrar as estratégias que visem a interferir no núcleo das representações sociais de um determinado grupo. Os elementos periféricos de uma representação social estabelecem a interface entre $o$ núcleo central e a realidade concreta na qual a representação funciona e é elaborada ${ }^{(6)}$.

\section{RESULTADOS}

Após o processamento do corpus formado pelas evocações de todos os sujeitos no EVOC2003 os resultados indicaram que a média das Ordens Médias de Evocação (OME) foi de 2,5; a frequência média ficou estabelecida em 10 e a mínima 5. Obteve-se, assim, o quadro de quatro casas (Tabela 1).

Com a distribuição das palavras evocadas no quadro de quatro casas, no quadrante superior esquerdo encontram-se as palavras orientação (frequência de 40 e ordem de evocação 2,375) e prevenção (frequência de 28 e ordem de evocação 2,000 ), sendo estes os prováveis elementos centrais da representação dos ACS sobre educação em saúde. Esses termos apresentam 
Tabela 1 - Quadro de Quatro Casas das evocações ao termo indutor educação em saúde. Pará, 2009

\begin{tabular}{|c|c|c|c|c|c|}
\hline \multicolumn{6}{|c|}{$\overline{O M E}=2,5 ;$ Frequência mínima $=5 ;$ Frequência média $=10$} \\
\hline \multicolumn{2}{|l|}{ Frequência $>=10$} & \multirow{2}{*}{$\begin{array}{l}\text { OME }<=2,5 \\
\text { OME }\end{array}$} & \multicolumn{2}{|l|}{ Frequência $>=10$} & \multirow{2}{*}{$\begin{array}{l}\text { OME }>=2,5 \\
\text { OME }\end{array}$} \\
\hline Palavras & Frequência & & Palavras & Frequência & \\
\hline Orientação & 40 & 2,375 & Amor & 19 & 2,895 \\
\hline \multirow[t]{2}{*}{ Prevenção } & 28 & 2,000 & Bem-estar & 11 & 2,727 \\
\hline & & & Cuidado & 21 & 2,714 \\
\hline \multicolumn{2}{|l|}{ Frequência < 10} & $\mathrm{OME}<=2,5$ & \multicolumn{2}{|l|}{ Frequência $<=10$} & $\mathrm{OME}>=2,5$ \\
\hline Palavras & Frequência & OME & Palavras & Frequência & OME \\
\hline \multirow[t]{6}{*}{ Aprendizagem } & 9 & 2,444 & Acompanhamento & 5 & 2,778 \\
\hline & & & Conhecimento & 9 & 4,356 \\
\hline & & & Felicidade & 6 & 2,546 \\
\hline & & & Higiene & 8 & 2,889 \\
\hline & & & $\mathrm{Paz}$ & 6 & 4,330 \\
\hline & & & Preconceito & 6 & 2,998 \\
\hline
\end{tabular}

frequências entre 28 e 40 e, ao mesmo tempo, obtiveram médias de evocações inferiores a 2,5 , sendo as mais prontamente evocadas.

Os elementos que se encontram no quadrante superior direito são denominados de primeira periferia. A palavra amor sugere mais uma dimensão para a educação em saúde, a afetiva; as palavras bem-estar e cuidado ampliam a dimensão cuidativa presente no núcleo central.

Os elementos que se encontram no quadrante inferior direito são denominados de segunda periferia. Neste quadrante encontramos termos como higiene, que sugere uma dimensão física; paz e felicidade, que podem indicar uma dimensão social e/ou emocional; o termo acompanhamento, que complementa a dimensão educativa; e conhecimento, sugerindo uma dimensão cognitiva.

No quadrante inferior esquerdo (elementos de contraste), está o termo aprendizagem, reforçando o termo orientação (dimensão educativa), presente no núcleo central, que pode inferir a presença de uma prática pedagógica no dia-a-dia dos ACS.

\section{DISCUSSÃO}

Os ACS apresentam uma estrutura representacional positiva, fortemente marcada pela ideia de prevenção e orientação. Uma característica que merece destaque do suposto núcleo central é a presença de duas dimensões: a palavra orientação representa a dimensão funcional- educativa do agir dos ACS e a palavra prevenção, a dimensão normativa-cuidativa.

O caminho entre saúde e doença pode se realizar distanciando-se da doença, mas mantendo-a como foco (estratégias preventivas), ou aproximando-se da saúde como referência (estratégia de promoção) ${ }^{(7-8)}$. O núcleo central revela a construção histórica da educação em saúde no Brasil, marcada pela prevenção e orientação ${ }^{(9)}$.

O núcleo central é a base comum e consensual de uma representação social e emerge da memória coletiva e do sistema de normas do grupo social ${ }^{(10)}$. Segundo as diretrizes legais do Ministério da Saúde, os ACS devem priorizar a prevenção em consonância com os objetivos da equipe de saúde da família ${ }^{(11)}$. A presença do léxico prevenção no núcleo central reforça tal afirmação.

O conceito de experiência remete a um "campo onde se entrecruzam representações e práticas; subjetividade e objetividade; pensamento e ação; corpo e mente"(12). Como os ACS estão no início de carreira, este campo está em construção, é emergente, e assim as representações veiculadas nos dispositivos legais condicionam com mais intensidade as representações e práticas sociais dos sujeitos.

Nesse sentido, enfatizamos que o maior instrumento de trabalho dos ACS não são as balanças que carregam, tampouco as requisições de exames que podem fazer. Os ACS, ao entrarem em contato com a comunidade de que fazem parte, têm como principal dispositivo o próprio processo de educação em saúde; a fim de motivar as pessoas ao cuidado os ACS travam um diálogo único -uma via que se concretiza na orientação- visto que compreendem aquele universo linguístico e cultural ao mesmo tempo em que podem mediar as trocas entre o conhecimento popular e o científico e promover o cuidado -uma via que se operacionaliza na prevenção. 
Quando realizam orientação, os ACS têm o potencial de estabelecer profunda relação dialógica com a comunidade, o que pode levar a compreensão do processo saúde-doença numa perspectiva ampliada: um processo que envolve as condições de vida da população, aspectos religiosos, étnicos, territoriais, os saberes e práticas populares de cuidado, o imaginário, as representações; enfim, todos os elementos constituintes da cultura de uma comunidade.

Sobre aspectos cognitivos e emocionais, cabe destacar que o processo de mudança de comportamentos não passa exclusivamente pela cognição, mas pelas motivações e emoções dos sujeitos envolvidos no processo. O saber desenvolvido na educação em saúde também passa por uma consciência corporal, que pode ser facilitada e ampliada pelo profissional da saúde, se este estiver sensibilizado para essa dimensão $0^{(13)}$. Inferimos que ao evocarem orientação e prevenção (elementos estruturantes da representação), bem como os léxicos amor, cuidado, felicidade e higiene (elementos complementares da representação), estão sensibilizados para tal dimensão.

Os termos respeito e solidariedade apontam uma dimensão relacional; o termo preconceito, uma dimensão ética, e assim a representação de educação em saúde revela-se ampliada e alargada, podendo aproximar-se de uma perspectiva de aconselhamento ${ }^{(11)}$.

Há necessidade de superação do caráter meramente cognitivista e instrumental da educação em saúde, cujos princípios se apóiam exclusivamente no saber científico. Há um trabalho educativo a ser feito que extrapola o campo da informação ao integrar a consideração de valores, costumes, modelos e símbolos sociais que levam a formas específicas de condutas e práticas, dando importância aos saberes do senso comum na relação das pessoas com a doença ${ }^{(12)}$.

A relação da educação em saúde aos afetos nos faz pensar numa perspectiva amorosa de um processo educativo que se quer afetivo e também libertador ${ }^{(12)}$. A educação em saúde abrange universos amplos e complexos, focalizando o homem e todas as relações que este pode estabelecer com o mundo, com o outro e consigo próprio, podendo mediar transformações na sociedade. Podemos afirmar que a educação em saúde é utopia, é sonho possível, que se concretiza com a ação de sujeitos históricos e sociais e é, acima de tudo, possibilidade e esperança de que representações negativas se transformem, que preconceitos sejam desconstruídos, que novas/ outras representações sejam reconstruídas pela ação humana a fim de fundarmos um mundo mais solidário, mais humano, mais ético, com menos descuidado ${ }^{(12)}$.
Ao observar a estrutura representacional dos ACS no seu conjunto é possível relacionar o termo indutor educação em saúde a múltiplas dimensões: educativa, cuidativa, afetiva, física, relacional, cognitiva, social e ética, as quais configuram, em síntese, o conteúdo integral da representação, e indicam que a associação da realização dos cuidados com a saúde não depende somente de informações e conhecimentos. Ele é incorporado pela conscientização. A busca do cuidado está relacionada ao "querer cuidar-se", que ultrapassa o "saber". Este é impulsionado pela construção da consciência social do cuidado, através das experiências, do observar, do sentir, do partilhar com os outros sujeitos as situações que envolvem o viver ${ }^{(13)}$.

A compreensão da representação é a aproximação das vivências e do pensamento partilhado, sendo fundamental para que possamos compreender o indivíduo ou grupo social. Por meio da representação social podemos buscar conhecer as pessoas, e desenvolver estratégias de educação permanente fundamentadas na realidade apresentada.

\section{CONCLUSÃO}

A partir das evocações dos ACS, pode-se relacionar a representação social de educação em saúde às dimensões educativa, cuidativa, afetiva, física, relacional, cognitiva, social e ética, transcendendo os aspectos clínico-biológicos. Pode-se então vislumbrar uma possibilidade de não-conformidade com o modelo biomédico de assistência à saúde do usuário, a qual amplia a educação em saúde para uma relação de responsabilização, afetiva, de escuta, de fala, de interação de saberes, de geração de vínculos e autonomia.

Concluiu-se que a representação social de educação em saúde dos ACS está ligada à múltiplas perspectivas, o que exige uma atitude interdisciplinar e transversal nas ações de educação permanente. Não se limita a abordar conteúdos a serem tratados com a população, mas também abrir espaço na formação para os modos de se fazer isso, como tratá-los, com quais mediações, e qual finalidade e acima de tudo, de forma ética.

As implicações de tais representações para uma política de educação permanente são as seguintes: há que se investigar o processo de conhecimento e atuação do ACS no que diz respeito à educação em saúde, com vistas a identificar suas representações; há que se instrumentalizar esses atores para realizar práticas educativas dialógicas a favor da qualidade de vida dos usuários; há que se buscar soluções aos problemas 
enfrentados no dia-a-dia e promover a transformação da prática profissional dos ACS, considerando as vivências e experiências de cada um, em que o aprender e o ensinar estão ligados ao cotidiano de todos os ACS; há que se buscar melhorias das condições de trabalho a favor de um agir ético, assim como há que se manter o respeito à categoria profissional dos ACS como sujeitos que sentem, sofrem, amam, educam, que se preocupam e cuidam do próximo. Há que se alargar a concepção e a abrangência da educação em saúde para os demais níveis do sistema.

\section{REFERÊNCIAS}

1. Ministério da Saúde (BR). Caderno de Educação Popular e Saúde. Brasília: Ministério da Saúde; 2007.

2. Candeias NMF. Conceitos de educação e de promoção em saúde: mudanças individuais e mudanças organizacionais. Rev saude publica. 1997;31(2):23-9.

3. Ferraz L, Aertz DRGC. O cotidiano de trabalho do agente comunitário de saúde no PSF em Porto Alegre. Cienc. saude coletiva. 2005;10(2):48-56.

4. Nunes MO, Almeida BA, Homem CR, Melo MCI. O agente comunitário de saúde: construção da identidade desse personagem híbrido e polifônico. Cad. saude publica. 2002;18(6):87-94.

5. Barbosa VBA. Educação permanente na estratégia saúde da familia: uma proposta a ser construída. Botucatu: Unesp; 2008.

6. Sá CP. Núcleo central das representações sociais. Petrópolis: Vozes; 2002.

7. Maciel MED, Borges PKO, Sales CM, Renovato RD. Educação em saúde na percepção de agentes comunitários de saúde. Cogitare enferm. 2009;14(2):340-6.

8 Buss PM. Uma introdução ao conceito de promoção da saúde. In: Czeresnia D. Promoção da saúde: reflexões, conceitos, tendências. Fiocruz: Rio de Janeiro; 2003. p.45-58.

9. Abric JC. A abordagem estrutural das representações sociais. In: Moreira ASP, Oliveira DC, organizadores. Estudos interdisciplinares em representação social. $2^{\mathrm{a}}$ ed. Goiânia: AB; 2000. p. 56-69.

10. Gazzinelli MF. Educação em saúde: aspectos históricos e conceituais. In: Gazzinelli MF, Marques RC, Reis DC. Educação em saúde: teoria, método e imaginação. Belo Horizonte: UFMG; 2006. p. 9-17.
11. Pereira APCM, Servo MLS. A enfermeira e a educação em saúde. Rev. baiana saúde pública. 2006;30(1):7-18.

12. Freire P. Pedagogia da autonomia. $21^{\mathrm{a}}$ ed. São Paulo: Cortez; 2009.

13. Coelho MJ. Produtos dos cuidados de enfermagem. Rev. bras. enferm. 2009;62(6):919-22.

Cogitare Enferm. 2012 Jan/Mar; 17(1):15-20 